\title{
Study on Gd and Mg co-doped ceria electrolyte for intermediate temperature solid oxide fuel cells
}

\author{
Feng-Yun Wang ${ }^{\mathrm{a}, \mathrm{b}, *}$, Songying Chen ${ }^{\mathrm{a}}$, Qin Wang ${ }^{\mathrm{a}}$, \\ Shuxin $\mathrm{Yu}^{\mathrm{a}}$, Soofin Cheng ${ }^{\mathrm{c}}$ \\ anstitute of Catalysis, Zhejiang University (Xixi Campus), Hangzhou 310028, PR China \\ ${ }^{\mathrm{b}}$ Chemistry Department, Foshan University, Foshan 528000, PR China \\ ${ }^{\mathrm{c} C h e m i s t r y}$ Department, National Taiwan University, Taipei 106, Taiwan
}

Received 18 November 2003; received in revised form 4 February 2004; accepted 2 April 2004

Available online 3 August 2004

\begin{abstract}
A Gd and Mg co-doped ceria electrolyte $\mathrm{Ce}_{0.85} \mathrm{Gd}_{0.1} \mathrm{Mg}_{0.05} \mathrm{O}_{1.9}$ (CGM) was prepared by sol-gel method. Its conductivity behavior was studied and compared with those of singly doped ceria electrolytes $\mathrm{Ce}_{0.9} \mathrm{Mg}_{0.1} \mathrm{O}_{1.9}(\mathrm{CM} 10)$ and $\mathrm{Ce}_{0.9} \mathrm{Gd}_{0.1} \mathrm{O}_{1.95}(\mathrm{CGO})$. By using CGM as the electrolyte, a fuel cell was fabricated with a Ni/CGM anode and a $\mathrm{La}_{0.6} \mathrm{Sr}_{0.4} \mathrm{Co}_{0.2} \mathrm{Fe}_{0.8} \mathrm{O}_{3}$ (LSCF)/CGM composite cathode. Its performance was compared with that of CGO based fuel cells. Both the CM10 and CGM electrolytes were ceria based solid solutions. The dopant Mg ${ }^{2+}$ might be situated in the interstitials of the crystal lattice of $\mathrm{CeO}_{2}$. The co-doped CGM showed a higher conductivity in air at 773-973 K in comparison to that of CGO and CMO. The CGM based fuel cell also showed higher open circuit voltage (OCV) and higher maximum power density (MPD) than the CGO based cell at 773-973 K. The MPD of the fuel cells were improved further by using composite cathode of LSCF/

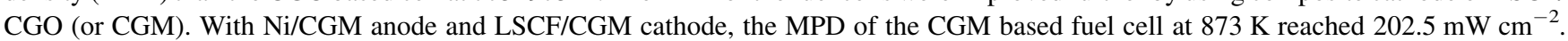
(C) 2004 Elsevier B.V. All rights reserved.
\end{abstract}

Keywords: Solid oxide fuel cell; Electrolyte; Gd and Mg co-doped ceria; Conductivity

\section{Introduction}

Fuel cells have received great attention as environmentally friendly and efficient means to generate electric power for both stationary and mobile applications [1]. Among the various fuel cells investigated, solid oxide fuel cells (SOFCs) have the following advantages [1-3]: (1) ease use and durability of the solid (rather than liquid) electrolyte materials, (2) high energy conversion efficiency (up to 60$80 \%$ ), (3) wide variety of fuels (including hydrocarbons and oxygenates), (4) non-noble-metal electrode, and (5) no threat from $\mathrm{CO}$ poisoning. However, the conventional SOFCs incorporating yttria stabilized zirconia (YSZ) as the electrolyte are operated at very high temperatures, ca.

\footnotetext{
* Corresponding author. Present address: Chemistry Department, National Taiwan University, Taipei 106, Taiwan. Fax: +886 223636359.

E-mail address: Twwfy@yahoo.com.hk (F.-Y. Wang).
}

$1173-1273 \mathrm{~K}$. This places considerable constraints on the materials that can be used for interconnects and balance of plant (e.g. the interconnect material $\mathrm{LaCrO}_{3}$ is prone to degradation during long-term operation) [2]. Also, it requires more time and energy to start-up [3]. If the operating temperature can be lowered down to 773-973 K, which is termed the intermediate temperature (IT) range, it will be possible to use stainless steel for interconnects and balance of plant [2]. This would make the fabrication of SOFCs much more cost-effective, particularly for vehicular applications. However, in the IT range, YSZ shows low conductivity, which leads to high inner resistance of the fuel cells. In order to develop fuel cells having low inner resistance at IT, three research routes have been adopted: (1) reducing the thickness of the electrolyte (especially YSZ) film [1,3]; (2) developing new electrolyte materials of higher ionic conductivity for operation at IT [1-4]; and (3) improving the electrodes and catalysts to reduce the over- 
potentials $[3,5,6]$. So far, the thickness of electrolytes can be reduced to $1-10 \mu \mathrm{m}$ [2-3]. Further reduction would lead to reliability problem with electrolyte integrity. Studies on new electrolytes have led to the discovery of $\mathrm{Ce}_{1-x} \mathrm{Gd}_{x} \mathrm{O}_{2-y}(0.1$ $\leq x \leq 0.2$, CGO) [7] and $\mathrm{La}_{0.9} \mathrm{Sr}_{0.1} \mathrm{Ga}_{0.8} \mathrm{Mg}_{0.2} \mathrm{O}_{2.85}$ (LSGM) $[4,8,9]$, which showed higher ionic conductivities than YSZ in the IT range. LSGM showed a wider ionic domain than CGO, but was not as stable and compatible as CGO [9]. In many studies on CGO based fuel cells, $\mathrm{La}_{1-x} \mathrm{Sr}_{x} \mathrm{Co}_{1-y} \mathrm{Fe}_{y} \mathrm{O}_{3-z}$ (LSCF) was used as the cathode $[1,2,10]$, and $\mathrm{Ni} / \mathrm{YSZ}[1,2]$ or Ni/CGO $[3,10]$ as the anode. For example, Sahibzada et al. [2] fabricated a fuel cell by using a $5 \mu \mathrm{m}$ thick film of CGO as the electrolyte, Ni/YSZ as the anode, and LSCF as the cathode. Its maximum power density (MPD), using $67.5 \% \mathrm{H}_{2} / \mathrm{CO}_{2}$ as fuel, was 126,65 , and $32 \mathrm{~mW} \mathrm{~cm}^{-2}$ at 923,873 , and $823 \mathrm{~K}$, respectively.

Although much progress has been made, the CGO based fuel cells reported so far has not met the commercial requirement yet. In order to further improve the electrolytes, co-doping method has been used in recent years and was found effective [11,12]. Although many co-doped ceria have been investigated, such as $\mathrm{Ce}_{1-x-y} \mathrm{Gd}_{x} \mathrm{Pr}_{y} \mathrm{O}_{2-z}$ [13]; $\mathrm{Ce}_{1-x-y} \mathrm{Sm}_{x} \mathrm{La}_{y} \mathrm{O}_{2-z}$ [12]; $\mathrm{Ce}_{1-x-y} \mathrm{Y}_{x} \mathrm{La}_{y} \mathrm{O}_{2-z}$ [14], and $\mathrm{Ce}_{1-x-y-z} \mathrm{Gd}_{x} \mathrm{Sm}_{y} \mathrm{Y}_{z} \mathrm{O}_{2-d}$ [11], etc., to the best of our knowledge there is no studies reported on $\mathrm{Gd}$ and $\mathrm{Mg}$ codoped Ceria. Considering the low cost and high stability of $\mathrm{MgO}$ and possible co-doping effect, $\mathrm{Gd}$ and $\mathrm{Mg}$ co-doped ceria (CGM) was prepared and characterized in this research. Its conductivity was compared with singly doped CGO and $\mathrm{Ce}_{1-\mathrm{x}} \mathrm{Mg}_{\mathrm{x}} \mathrm{O}_{2-\mathrm{y}}(\mathrm{CMO})$. A fuel cell fabricated with CGM and the electrodes was studied and compared with other two fuel cells with different electrolyte or/and electrodes.

\section{Experimental}

\subsection{Powder synthesis}

\subsubsection{CGM powder}

Electrolyte powder was synthesized by sol-gel method. According to the given composition $\left(\mathrm{Ce}_{0.85} \mathrm{Gd}_{0.1} \mathrm{Mg}_{0.05} \mathrm{O}_{1.9}\right)$, nitrates of $\mathrm{Ce}, \mathrm{Gd}$, and $\mathrm{Mg}$ (A.R.) were weighed and dissolved in distilled water in which a little citric acid and polyethylene glycol was added. The obtained solution was evaporated on a water bath at $353 \mathrm{~K}$ until it was gradually gelled. The gel was dried at $378 \mathrm{~K}$, ground and calcined at $973 \mathrm{~K}$ for $4 \mathrm{~h}$, and then ground again to fine powder.

\subsection{2. $C G O$ powder}

$\mathrm{Ce}_{0.9} \mathrm{Gd}_{0.1} \mathrm{O}_{1.95}(\mathrm{CGO})$ powder was prepared in a similar way as that for CGM but without $\mathrm{Mg}$.

\subsubsection{CMO powder}

$\mathrm{Ce}_{1-x} \mathrm{Mg}_{x} \mathrm{O}_{2-y}(x=0.05-0.2)$ powders were prepared in a similar way as that for CGM but without $\mathrm{Gd}$. The $\mathrm{Ce}_{0.9} \mathrm{Mg}_{0.1} \mathrm{O}_{1.9}$ compound is termed as CM10.

\subsubsection{LSCF powder}

LSCF powder was prepared by solid-state reaction. According to the given composition $\left(\mathrm{La}_{0.6} \mathrm{Sr}_{0.4} \mathrm{Co}_{0.2}\right.$ $\mathrm{Fe}_{0.8} \mathrm{O}_{3}$ ), reagent graded $\mathrm{La}_{2} \mathrm{O}_{3}, \mathrm{Fe}_{2} \mathrm{O}_{3}, 2 \mathrm{CoCO}_{3} .3$ $\mathrm{Co}(\mathrm{OH})_{2} \cdot n \mathrm{H}_{2} \mathrm{O}$, and $\mathrm{SrCO}_{3}$ were mixed, and ball milled for $2 \mathrm{~h}$ in ethanol. After drying, it was calcined at $1273 \mathrm{~K}$ for $10 \mathrm{~h}$ and $1473 \mathrm{~K}$ for $5 \mathrm{~h}$, and then ground into powder.

\subsection{Electrode preparation}

\subsubsection{Ni/CGM anode}

$\mathrm{Ni} / \mathrm{CGM}$ anode was made by a mixture of CGM electrolyte powder (42 vol.\%), NiO powder (A.R. 42 vol.\%), and carbon/graphite powder (16 vol.\%). The mixture was ball milled for $2 \mathrm{~h}$ and then pressed into a pellet. The pellet was sintered at $1273 \mathrm{~K}$ for $5 \mathrm{~h}$ and $1673 \mathrm{~K}$ for $2 \mathrm{~h}$ to remove the carbon/graphite and form a porous structure composite anode (diameter: $10-12 \mathrm{~cm}$, thickness: $0.5-1.2 \mathrm{~mm}$ ).

\subsection{2. $L S C F / C G M$ cathode}

The LSCF/CGM cathode was prepared in a way similar to that of $\mathrm{Ni} / \mathrm{CGM}$ anode, but $\mathrm{NiO}$ powder and the sintering temperature of $1673 \mathrm{~K}$ were replaced by the LSCF powder and $1573 \mathrm{~K}$. The prepared cathode material was then ball milled into powder.

\subsection{Fuel cell fabrication}

The Ni/CGM anode pellet was used as a physical support for the CGM electrolyte film. A suspension of CGM, containing an organic solvent and a plasticizer, was tape-cast onto one side of the anode support. The assembly was sintered at $1723 \mathrm{~K}$ for $5 \mathrm{~h}$ to form a dense impermeable CGM film of approximately 15-25 $\mu \mathrm{m}$ in thickness. On top of the CGM film, the powder LSCF/CGM cathode material suspending in an organic solvent, was tape-cast on it. After drying and sintering at $1523 \mathrm{~K}$ for $4 \mathrm{~h}$, two pieces of Pt mesh were attached, with Pt paste, to the cathode and anode surfaces to act as current collectors. After drying and calcining at $1073 \mathrm{~K}$ for $1 \mathrm{~h}$, electrical connections to the cell were made by spot welding Pt wire to the Pt mesh current collectors. The whole assembly was placed, like a cap, over one end of an open ceramic pipe ( $8 \mathrm{~mm}$ in inner diameter) with the cathode facing outwards in order to be exposed to air and the anode facing into the pipe in order to be exposed to fuel contained within the pipe. A ceramic adhesive was applied between the cell edge and pipe rim, and subsequently heated gradually from $353 \mathrm{~K}$ to $973 \mathrm{~K}$ to form a gas tight seal. The fuel cell was denoted as LC-CGMNC. Here, LC and NC stand for LSCF/CGM composite cathode and NiO/CGM composite anode, respectively.

For comparison, two other fuel cells were fabricated similarly. One was fabricated with $\mathrm{CGO}$ electrolyte, $\mathrm{Ni} /$ CGO anode, and LSCF cathode, denoted as L-CGO-NC. Another, denoted as LC-CGO-NC, was fabricated in the same way, but LSCF cathode was replaced by LSCF/CGO 
cathode. Here L, LC, and NC stand for LSCF cathode, LSCF/CGO composite cathode and NiO/CGO composite anode, respectively.

\subsection{Characterization}

\subsubsection{Electrolyte characterization}

The crystal structure of the electrolytes were characterized by X-ray diffraction (XRD, Rigaku D/max-IIB). For conductivity measurement, electrolyte powder was pressed into raw pellets with a die of $13 \mathrm{~mm}$ diameter. The raw pellets were sintered at $1723 \mathrm{~K}$ for $5 \mathrm{~h}$ into dense pellets. The relative densities of the dense pellets were measured with Archimedes' method and found to be higher than 95\%. On both sides of the dense pellets, Pt paste was applied, and then sintered at $1073 \mathrm{~K}$ for $1 \mathrm{~h}$ to form Pt electrodes. Pt wires were attached to the electrodes using Pt paste and then sintered again at $1073 \mathrm{~K}$ for $1 \mathrm{~h}$. After 40 min equilibrium at a constant temperature between 673 and $973 \mathrm{~K}$, the total resistances of the dense pellets were measured with an electric-bridge (QJ31), and were used to calculate the conductivities of the dense pellets.

\subsubsection{Fuel cell characterization}

The cell-pipe assembly was placed into a tubular furnace with the cathode exposed to air in the furnace. A piece of long thin steel feed line was inserted through the open end of the pipe, running concentric along the inside of the pipe. This allowed a fuel feed to be preheated to the furnace temperature before passing through a diffuser that dispersed the fuel across the anode. After the reaction at the anode, the spent fuel flowed back in the opposite direction between the outside of the feed line and inside of the pipe (all the piping materials had been tested in the absence of the fuel cell and no pre- or post-reaction was detected). Electromotive forces (EMFs) of fuel cells were measured using a potentiometer. $I-V$ characteristics were determined by measuring current and voltage under variable loads. The temperature of the sample was measured with a thermocouple attached close to the sample and controlled by a temperature-programmed controller.

\section{Results and discussion}

\subsection{Crystal structures of electrolytes}

Fig. 1a-c showed the XRD patterns of pure $\mathrm{CeO}_{2}$ and the CM10 electrolyte before and after heat treatment in 1$6 \% \mathrm{H}_{2} / \mathrm{N}_{2}$ at $300-973 \mathrm{~K}$ for $1-10 \mathrm{~h}$. Both patterns of CM10 are similar to that of pure ceria except that the $2 \theta$ values in the three patterns shifted in an order of $a>b>c$. This result indicated that the CM10 electrolyte was ceria based solid solution whether being heat-treated or not. The dopant $\mathrm{Mg}^{2+}$ in CM10 might be seated in the lattice interstitials rather than substituting the lattice site of $\mathrm{Ce}^{4+}$.
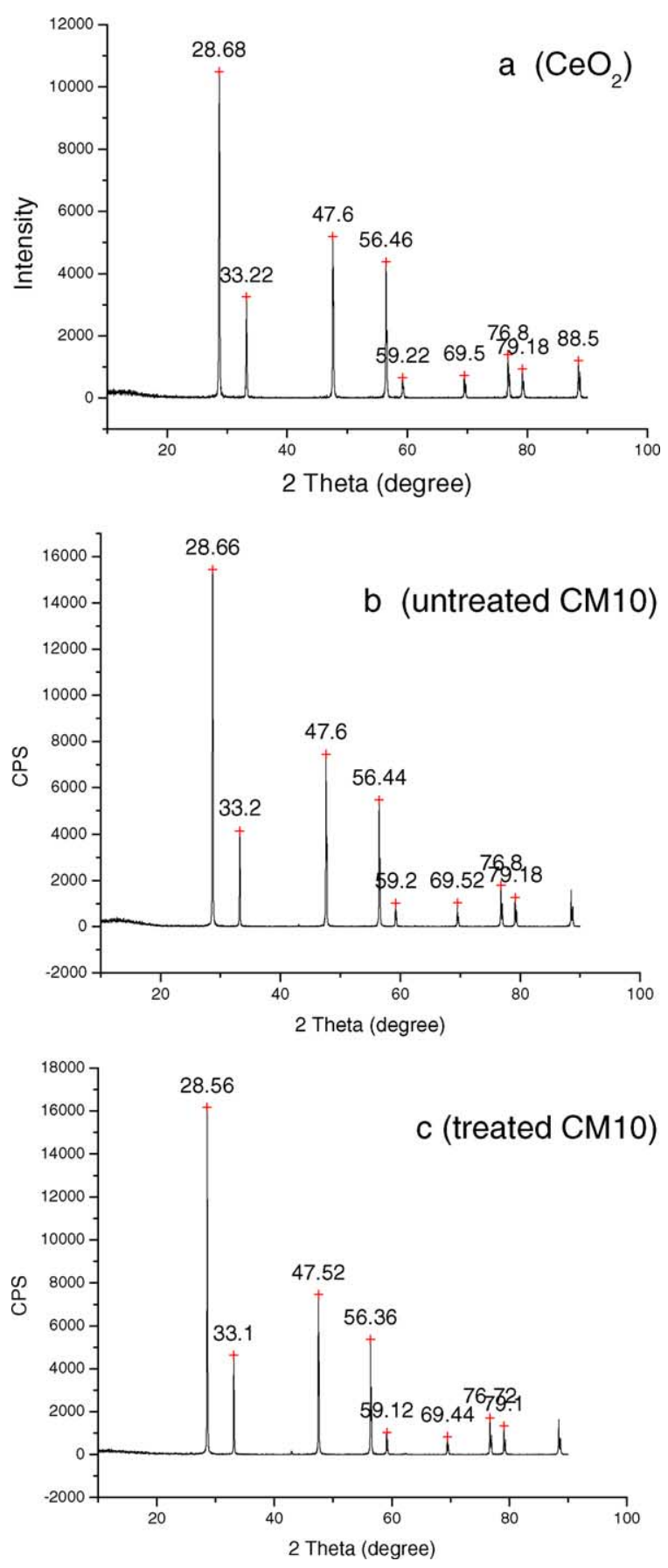

Fig. 1. XRD patterns of pure $\mathrm{CeO}_{2}$ (a) and $\mathrm{CM} 10$ electrolytes before (b) and after (c) the heat treatment in $1-6 \% \mathrm{H}_{2} / \mathrm{N}_{2}$ at $300-973 \mathrm{~K}$ for $1-10 \mathrm{~h}$.

Otherwise, the $2 \theta$ for CM10 should be greater than those of pure $\mathrm{CeO}_{2}$ because $\mathrm{Mg}^{2+}$ is much smaller than $\mathrm{Ce}^{4+}$. Through the heat-treatment in reducing atmosphere, a few $\mathrm{Ce}^{4+}$ ions in CM10 were probably reduced to $\mathrm{Ce}^{3+}$ of larger size [2], which led to an increase in lattice constant and in turn, smaller $2 \theta$ in the XRD pattern (Fig. 1c).

Fig. 2a and $\mathrm{b}$ show the XRD patterns of CGO and CGM electrolytes. They are all similar to that of ceria (Fig. 1a) except a slight shift in $2 \theta$, indicating that both CGO and 

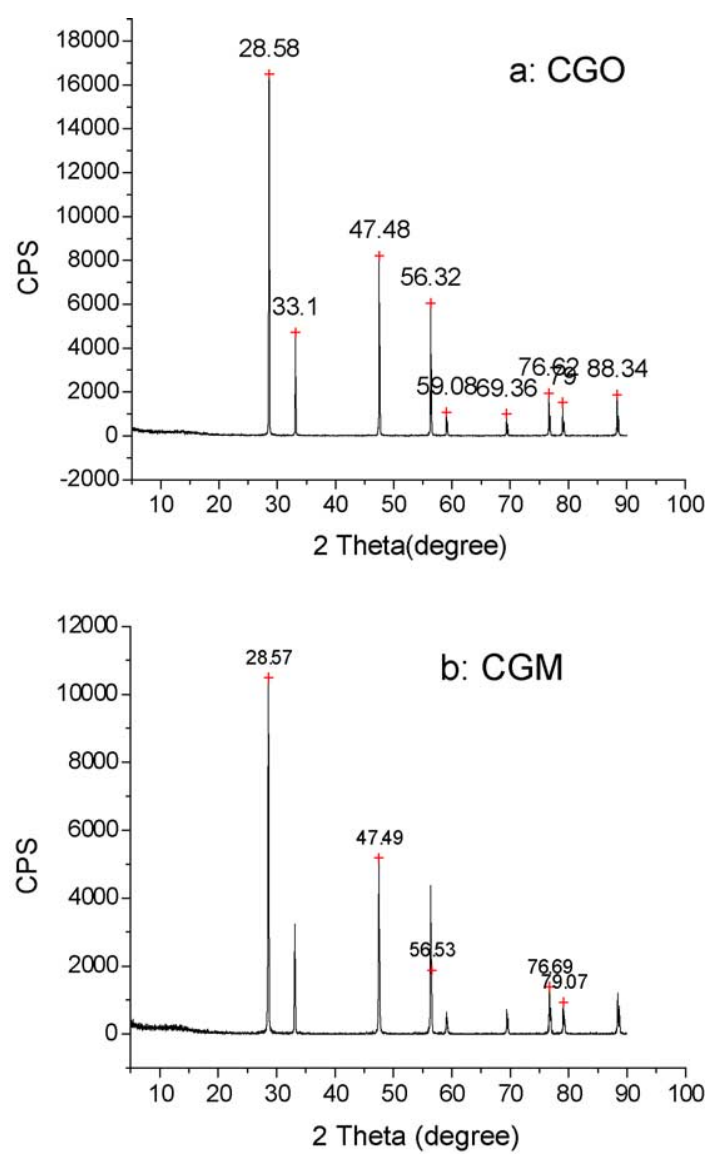

Fig. 2. XRD patterns of different electrolytes: (a) CGO; (b) CM10.

CGM are ceria based solid solutions. Because the sizes of $\mathrm{Gd}^{3+}$ and $\mathrm{Mg}^{2+}$ are different from that of $\mathrm{Ce}^{4+}$, the $2 \theta$ values in Fig. 2 are slightly different from those of ceria.

\subsection{Conductivities of electrolytes}

In the case of doped ceria compounds, most of the conductivity in air is oxide ionic conductivity (>99.5\%) [15], and the contribution of electronic conductivity is very small [16]. In this study, the conductivity in air was taken as the oxide ionic conductivity.

The conductivities of CM10 in air before and after the heat treatment are given in Fig. $3 a$ and b. Before the heat treatment, the conductivity of CM10 was very low and reached $1.4 \times 10^{-5} \mathrm{~S} \mathrm{~cm}^{-1}$ at $973 \mathrm{~K}$, which is very close to the value of $1.46 \times 10^{-5} \mathrm{~S} \mathrm{~cm}^{-1}$ reported in the literature [17]. However, after the heat treatment, the conductivity of CM10 increased a lot, and reached $2 \times 10^{-3} \mathrm{~S} \mathrm{~cm}^{-1}$ at $973 \mathrm{~K}$, which is much higher than that before the treatment. This dramatic increase in conductivity probably resulted from the formation of extra oxygen vacancies and a portion of $\mathrm{Ce}^{4+}$ ions being reduced to $\mathrm{Ce}^{3+}$ during the heat treatment $[12,18]$. The stability of CM10 electrolyte was also investigated by in situ monitoring the changes of conductivity at $973 \mathrm{~K}$ as a function of time for $70 \mathrm{~h}$. It was found that, at $973 \mathrm{~K}$, the conductivity of CM10 electrolyte after the heat

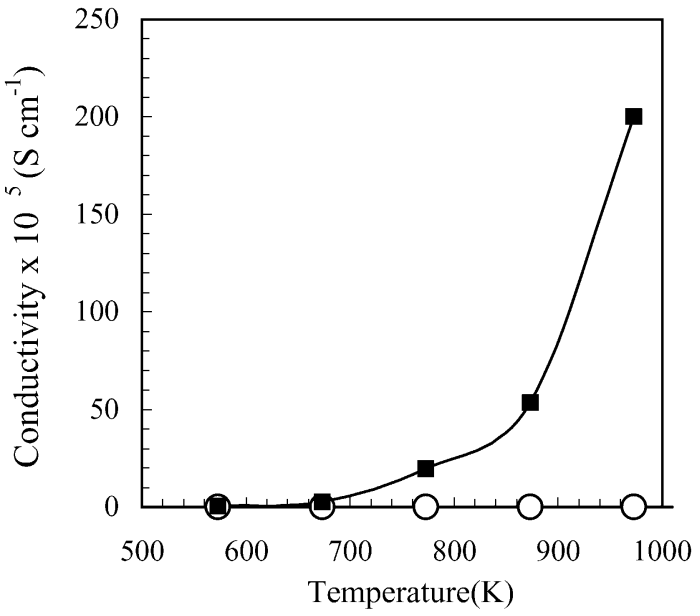

Fig. 3. Effect of temperature on conductivity in air of CM10 electrolyte before (circle) and after (solid square) the heat treatment in $6 \% \mathrm{H}_{2} / \mathrm{N}_{2}$ at $973 \mathrm{~K}$.

treatment did not change apparently with time, indicating that the electrolyte is very stable. The above heat-treatment effect, however, was not detectable for $\mathrm{Ca}$-doped $\mathrm{CeO}_{2}, \mathrm{Sr}-$ doped $\mathrm{CeO}_{2}$, and $\mathrm{CGO}$ electrolytes. This implies that the heat-treatment effect might be related to the special structure of CM10.

The effect of $\mathrm{Mg}$ content on the heat-treatment effect was also investigated. It was found that the heat-treatment effect changed with $\mathrm{Mg}$ content and reached its maximum at $\mathrm{Mg}$ content of ca. $10 \mathrm{~mol} \%$. This is consistent with the conductivity results [10], i.e., the conductivity of $\mathrm{Ce}_{1-x} \mathrm{Mg}_{x} \mathrm{O}_{1-y}$ reaches the maximum at $x=0.1$. The effect of gas atmosphere on the heat-treatment effect was investigated too. It was found that the concentration of $\mathrm{H}_{2}$ must be less than $6 \mathrm{~mol} \%$, otherwise, the reverse results would be observed.

Fig. 4 shows the conductivity of CGM and CGO electrolytes in air. CGO gives a little higher conductivity, 0.077 $\mathrm{S} \mathrm{cm}^{-1}$ at $973 \mathrm{~K}$, than the literature data $\left(0.058 \mathrm{~S} \mathrm{~cm}^{-1}\right)$

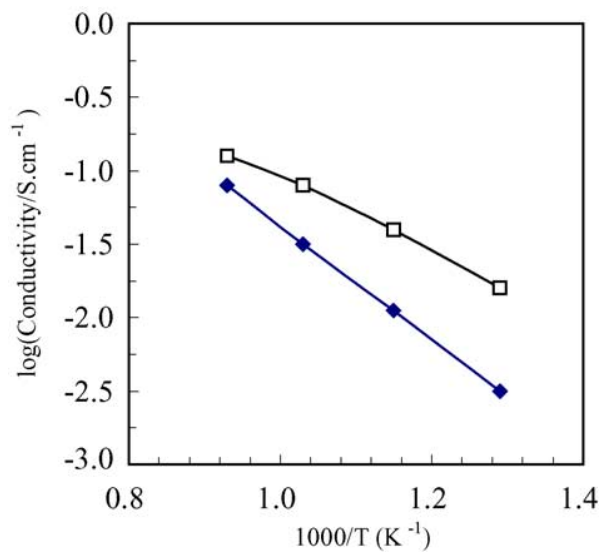

Fig. 4. Effect of temperature on conductivities $(\sigma)$ of electrolytes in air (open square: CGM, solid square: CGO). 
[19], and CGM shows even higher conductivity than CGO, especially at low temperature range. This result might be due to co-doping effect and the formation of extra oxygen vacancies caused by the addition of $\mathrm{MgO}$. Furthermore, the $\mathrm{Mg}$ content in CGM was varied in $2-10 \mathrm{~mol} \%$ and it was found that about $5 \mathrm{~mol} \%$ is the best. This is because the content of oxygen vacancies in the electrolyte also needs an optimum value.

\subsection{Fuel cell performance}

Since CGM has higher conductivity than CGO, a fuel cell fabricated with it was studied. Fig. 5 shows the currentvoltage characteristics of the single fuel cells at $773 \mathrm{~K}$ and $873 \mathrm{~K}$ using $6 \% \mathrm{H}_{2} / \mathrm{N}_{2}$ as the fuel and air as the oxidant. The results are summarized as follows: (1) all the open circuit voltages (OCV) of the fuel cells are lower than those predicted by the Nernst Equation (about 1V) [7]; (2) the OCV value of LC-CGM-NC is larger than those of LCCGO-NC and L-CGO-NC; and (3) the temperature increase has a negative effect on the OCV.

A trace amount of gas leakage through micropores in the electrolyte film and more possibly through the ceramic adhesive seals may have caused some of the loss of OCV. Another possible reason of the OCV loss is that in addition to the higher ionic conductivity, ceria based electrolytes have some electronic conductivity [3]. Hence, under open circuit conditions there would be some short-circuiting, which leads to the loss of OCV. Because CGM has higher ionic conductivity and possibly higher compaction than CGO, CGM based fuel cell showed higher OCV than the CGO based one. The electronic conductivity of electrolytes would increase with the increase in temperature, and that in turn caused the loss of the OCV.

The linear current-voltage relationship in Fig. 5 indicates ohmic behavior, and the cell resistances can be calculated from the slope of the lines. Of the three cells, LC-CGM-NC

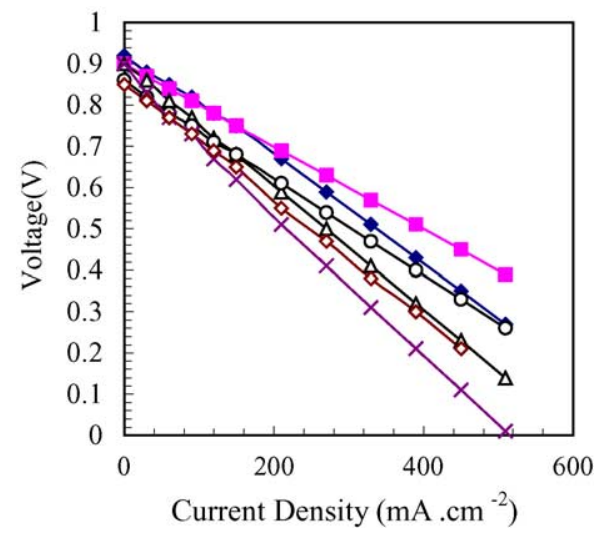

Fig. 5. Dependence of voltage on current density of fuel cells (fuel: $6 \% \mathrm{H}_{2} /$ $\mathrm{N}_{2}$; oxidant: air). ( ) LC-CGM-NC $773 \mathrm{~K},(\boldsymbol{\square})$ LC-CGM-NC $873 \mathrm{~K},(\triangle)$ LC-CGO-NC $773 \mathrm{~K}$, (○) LC-CGO-NC $873 \mathrm{~K},(\times)$ L-CGO-NC $773 \mathrm{~K},(\diamond)$ L-CGO-NC $873 \mathrm{~K}$.

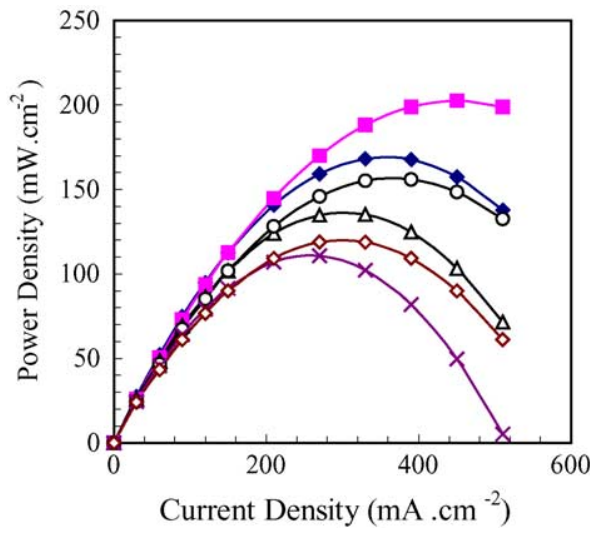

Fig. 6. Dependence of power density on current density of fuel cells (fuel: $6 \% \mathrm{H}_{2} / \mathrm{N}_{2}$; oxidant: air). ( ) LC-CGM-NC $773 \mathrm{~K}$, (ם) LC-CGM-NC $873 \mathrm{~K},(\triangle)$ LC-CGO-NC $773 \mathrm{~K},(\bigcirc)$ LC-CGO-NC 873K, (×) L-CGONC 773K, $(\diamond)$ L-CGO-NC $873 \mathrm{~K}$.

cell is of the minimum total cell resistance of $1.0 \Omega \mathrm{cm}^{2}$ at $873 \mathrm{~K}$.

Fig. 6 shows the current-power profiles of the single fuel cells at $773 \mathrm{~K}$ and $873 \mathrm{~K}$ with $6 \% \mathrm{H}_{2} / \mathrm{N}_{2}$ as the fuel and air as the oxidant. The MPD of LC-CGM-NC cell reached 168.3 and $202.5 \mathrm{~mW} \mathrm{~cm}^{-2}$ at $773 \mathrm{~K}$ and $873 \mathrm{~K}$, respectively, higher than those of the other two comparative fuel cells and some other results reported in the literatures [1-8]. The MPD of the fuel cells changes in an order of LC-CGM-NC > LC-CGO-NC > L-CGO-NC. This suggests that using codoped electrolyte and composite cathode could enhance the power output of the fuel cells. This is because the co-doped electrolyte usually shows higher ionic conductivity [11], and the composite cathode usually shows lower polarization [3].

\section{Conclusions}

CGM electrolyte was found to be a ceria based solid solution. It showed higher conductivity at IT (773-973 K) than the singly doped CGO and CM10. Co-doping was found to effectively enhance the conductivity. Because of this effect, the MPD of CGM based fuel cells at IT was found to be higher than that of CGO based ones, and it might be improved further by using composite cathode of LSCF/ CGM. The CM10 electrolyte was also a ceria based solid solution, but its dopant might be located in the interstitials of the $\mathrm{CeO}_{2}$ lattice, rather than on the $\mathrm{Ce}^{4+}$ sites. After a heattreatment in mild reducing atmosphere, the conductivity of CM10 in air increased dramatically.

\section{References}

[1] M. Sahibzada, B.C.H. Steele, K. Zheng, R.A. Rudkin, I.S. Metcalfe, Catal. Today 38 (1997) 459

[2] M. Sahibzada, B.C.H. Ssteele, K. Hellgardt, D. Barth, A. Effendi, D. Mantzavinos, I.S. Metcalfe, Chem. Eng. Sci. 55 (2000) 3077. 
[3] R. Doshi, V.L. Richards, J.D. Carter, X. Wang, M. Krumpelt, J. Electrochem. Soc. 146 (1999) 1273.

[4] T. Fukui, S. Ohara, K. Marata, H. Yoshida, K. Miura, T. Inagaki, J. Power Sources 106 (2002) 142.

[5] M.T. Colomer, B.C.H. Steele, J.A. Kilner, Solid State Ionics 147 (2002) 41.

[6] C. Xia, M. Liu, Solid State Ionics 144 (2001) 249.

[7] B.C.H. Steele, J. Power Sources 49 (1994) 1.

[8] Feng, J.B. Goodenough, Eur. J. Solid State Inorg. Chem. 31 (1994) 663.

[9] K. Yamaji, T. Horita, M. Ishikawa, N. Sakai, H. Yokokawa, Solid State Ionics 108 (1998) 415

[10] S.J.A. Livermore, J.W. Cotton, R.M. Ormerod, J. Power Sources 86 (2000) 411
[11] J.V. Herle, D. Seneviratne, A.J. McEvoy, J. Eur. Ceram. Soc. 19 (1999) 837.

[12] T. Mori, J. Drennan, J.-H. Lee, J.-G. Li, T. Ikegami, Solid State Ionics 154/155 (2002) 461.

[13] S. Lubke, H.-D. Wiemhofer, Solid State Ionics 117 (1999) 229.

[14] H. Yoshida, H. Deguchi, K. Miura, M. Horiuchi, Solid State Ionics 140 (2001) 191

[15] H. Inaba, H. Tagawa, Solid State Ionics 83 (1996) 1.

[16] G.M. Christie, F.P.F. van Berkel, Solid State Ionics 3 (1996) 17.

[17] H. Yahiro, T. Ohuchi, K. Eguchi, H. Arai, J. Mater. Sci. 23 (1988) 1036.

[18] R.M. Ormerod, Chem. Soc. Rev. 32 (2003) 17.

[19] Q.X. Fu, S.W. Zha, W. Zhang, D.K. Peng, G.Y. Meng, B. Zhu, J. Power Sources 104 (2002) 73. 